\title{
AC 2009-577: LEARNING OUTCOMES ASSESSMENT OF A PROJECT-ABROAD PROGRAM IN SOUTH AFRICA: TOWARD "A BETTER ENGINEER IN THE REAL WORLD"
}

\section{Laura Hahn, University of Illinois, Urbana-Champaign}

Dr. Laura Hahn is a specialist in education at the University of Illinois at Urbana-Champaign. She consults with faculty in the College of Engineering on curriculum, instruction, teaching assistant development, and learning outcomes assessment. She has helped develop two project-abroad programs for students in the Department of Agricultural and Biological Engineering.

\section{Alan Hansen, University of Illinois, Urbana-Champaign}

Alan Hansen received his $\mathrm{PhD}$ from the University of KwaZulu-Natal in South Africa, where he joined the Department of Agricultural Engineering in 1979. In 1999 he accepted a position as an associate professor at the University of Illinois in the Department of Agricultural and Biological Engineering. His major fields of research and teaching are off-road vehicles, diesel engines and biofuels, as well as biomass production systems. He has led three project-based study abroad programs to South Africa in the last five years. 


\section{Learning Outcomes Assessment of a Project-Abroad Program in South Africa: Toward "A Better Engineer in the Real World"}

Key words: "project-based learning," "international," "assessment"

Introduction

The quotation in the title of this paper is a student's statement about the future impact of his project-abroad experience in South Africa. Indeed, study-abroad and project-abroad experiences are increasingly viewed as important for engineering students' careers. Assessing the student learning outcomes of such programs can benefit (a) the students, as they engage in self-reflection and communication about their experience, (b) the study-abroad program itself, for continual improvement, and (c) the engineering education community at large, as it seeks effective methods and models for preparing engineers for their work. To this end, we gathered and analyzed student reflections on their learning experiences in a collaborative engineering project between the University of Illinois at Urbana-Champaign and the University of KwaZulu-Natal in South Africa.

Background

The Association of American Colleges and Universities' LEAP (Liberal Education for America's Promise) initiative (2007) emphasizes global awareness and experience within its four sets of Essential Learning Outcomes that are critical for preparing university students for the twenty-first century. The "personal and social responsibility" domain includes:

- Civic knowledge and engagement—local and global

- Intercultural knowledge and competence

- Ethical reasoning and action

- Foundations and skills for lifelong learning

... through active involvement with diverse communities and real-world challenges ${ }^{1}$

Engineering education professional organizations and experts echo these themes in descriptions of high-quality engineers of the twenty-first century. ABET requires accredited programs to provide "the broad education necessary to understand the impact of engineering solutions in a global and societal context" (criterion h). The National Academy of Engineering also prioritizes the global dimension: "We aspire to a future where engineers are prepared to adapt to changes in global forces and trends and to ethically assist the world in creating a balance in the standard of living for developing and developed countries alike." The NAE further highlights the importance of communication skills and teamwork for the global context: "In the new century the parties that engineering ties together will increasingly involve interdisciplinary teams, globally diverse team members, public officials, and a global customer base."”2

Similar points are made in influential volumes such as Educating Engineers: Designing for the Future of the Field, ${ }^{3}$ and Educating the Engineer of 2020. ${ }^{4}$ Redish and Smith also consider 
global awareness and multicultural communication skills in their useful framework for engineering undergraduate education (Figure 1$):^{5}$

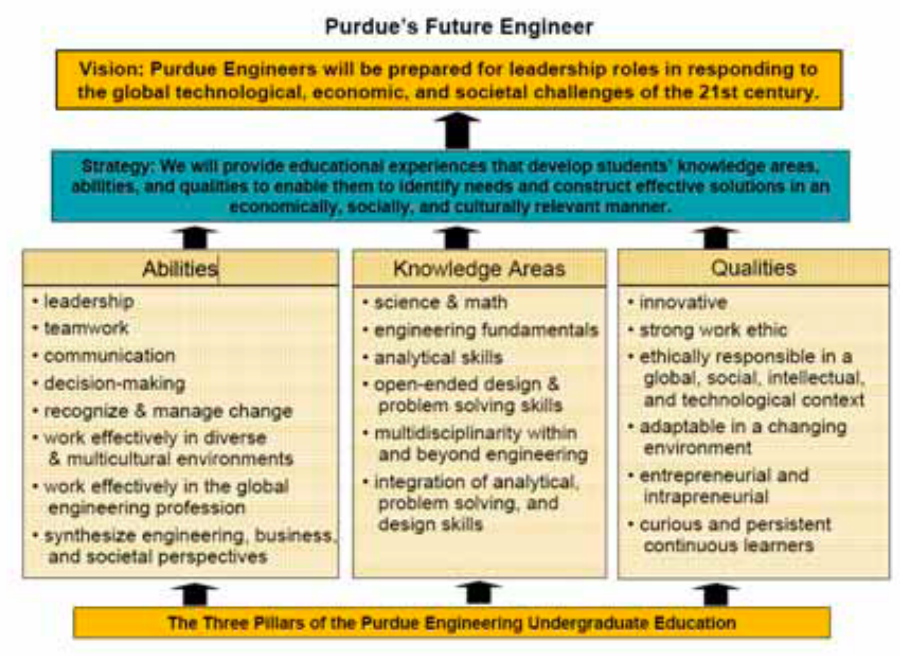

Figure 1. Purdue's future engineer (From Redish and Smith, 2008).

A significant learning experience abroad can be an important context in which students can develop the abilities, knowledge, and qualities that prepare them to be successful engineers. Parkinson conducted a survey of engineering study abroad programs and found a range of formats, goals, and practices - and noted that assessment of abilities, knowledge, and qualities such as the ones described in Figure 1 is an essential characteristic of effective programs. ${ }^{6}$

A variety of assessments have been used for engineering study-abroad experiences, with pre- and post-experience papers and interviews being quite common. In Worcester Polytechnic Institute's project-abroad program, student reports are assessed according to a rubric based on relevant ABET a-k outcomes. ${ }^{7,8}$ Georgia Tech and the University of Michigan have used a theory-based, standardized instrument to measure global competence and intercultural sensitivity (the Intercultural Development Inventory). ${ }^{9,10}$ The Purdue EPICS program emphasizes reflection as a way to assess learning outcomes. ${ }^{11}$ And Devon et al. used an "assessment of different conceptions of what it takes to be a good team player" with students from France and the US who were collaborating on design projects. ${ }^{12}$ There is clearly no "one-size-fits all" learning outcomes assessment rubric - largely because effective assessments are tailored to the purposes of the assessment as well as the learning context. ${ }^{13}$

Another emphasis in the literature on engineering education is project-centered learning (PCL): "design-oriented project-organized education which deals with the practical problems of constructing and designing on the basis of a synthesis of knowledge from many disciplines and is therefore having students learn to know how." 14 Smith et al. suggest that PCL is a "pedagogy of engagement," a practice that deepens student learning through "student-faculty contact, cooperation among students, and active learning."15 
Sheppard et al. advocate team-based PCL as a way to improve students' competencies in teamwork and communication strategies. They also found that capstone design courses (a type of PCL) promote student excitement, build "skills for professional practice," and engage students in integrating and synthesizing knowledge within engineering and across other disciplines. ${ }^{16}$

Service-learning is another pedagogical approach that is gaining momentum in engineering education. ${ }^{17}$ Service-learning combines experiential learning, community service, and participant reflection. Tsang describes the benefits of engineering service-learning for society, for the student participants, and for faculty members. ${ }^{18}$ Moffatt and Decker have emphasized the importance of the role of reflection for engineering students in service-learning projects, and provide useful guidelines for creating effective reflective questions and assignments. ${ }^{19}$

The context of this program

This four-week project-centered program was arranged to take place in South Africa for the first time in the summer of 2004, and was offered again in 2006 and 2008. Approximately the same format for the three visits was employed. The procedure followed in the program was first of all to set up a collaboration with the School of Bioresources Engineering and Environmental Hydrology (BEEH) at the University of KwaZulu-Natal (UKZN) in South Africa to facilitate student interaction via teamwork on mutually selected capstone design projects. Both undergraduate and graduate students were recruited from the Department of Agricultural and Biological Engineering at a large, public mid-western research-extensive university during the fall semester prior to the summer visit.

Early in the spring semester students were asked to rank their choice of three projects from a list provided by UKZN. Student teams were then created, comprising two to three students from each campus, to work on selected projects. These projects covered a broad range of design work, including a brush cutter for cutting sugar cane, a small-scale device heating and cooking device for low-income households, and a manually operated jab planter for the no-till soil conditions in southern Africa. In all cases the projects addressed engineering problems that were based on local community needs.

Communication among team members on both continents in the spring semester was encouraged to determine project goals and tasks to be addressed, culminating in a written progress report at the end of the semester. Students enrolled for the equivalent of an independent study or research and design thesis course. Informational meetings were held before travel to prepare students for the visit to South Africa. Students were also expected to review and procure material and equipment required for projects.

A schedule was formulated for the visit that provided students time to work on their projects in collaboration with South African students and faculty, and time to embark on planned travel excursions to different parts of the KwaZulu-Natal province to experience African cultures and environment. On arrival in South Africa the planned schedule was followed fairly closely and at the end of the visit student teams presented their work to faculty and students at UKZN. 
The objectives of this project-abroad experience are to expose students to a different culture and to the application of technologies appropriate to South African needs by collaborating on shortterm engineering design projects with South African students. ${ }^{20}$ For the third visit in 2008 a special effort was put into the development and application of more effective assessment procedures for the program. ${ }^{21}$ The purposes for a more thorough assessment emerged from a consideration of the American Higher Education's principles of good practice for assessing student learning, which include:

- Assessment is most effective when it reflects an understanding of learning as multidimensional, integrated, and revealed in performance over time. Learning entails not only what students know but what they can do with what they know; it involves not only knowledge and abilities but values, attitudes, and habits of mind that affect both academic success and performance beyond the classroom.

- Assessment works best when the programs it seeks to improve have clear, explicitly stated purposes.

- Assessment requires attention to outcomes but also and equally to the experiences that lead to those outcomes.

- Assessment fosters wider improvement when representatives from across the educational community are involved. Assessment is not a task for small groups of experts but a collaborative activity; its aim is wider, better-informed attention to student learning by all parties with a stake in its improvement.

- Assessment makes a difference when it begins with issues of use and illuminates questions that people really care about. ${ }^{22}$

Changes in the assessment process included more stakeholder involvement (with students, faculty, and an educational consultant), more focus on reflection during the experience (to align more with service-learning methods), and increased multidimensionality to the assessment methods. In addition to the previous outcomes assessment measures, three additional assignments were designed. The first was an additional pre-departure paper that encouraged students to reflect on their personal goals for the trip. Prompts were developed based on descriptions of "the engineer of 2020.",23

A second assignment for these students was a group weblog, or "blog." A blog is an online diary to which users can post entries, commentary, pictures, video, and other data that document their experiences. Because blogs allow for multimedia, as well as a conversational quality to the postings, they can provide a vivid and authentic picture of incidents and impressions. Student input was sought in the use of the blog; as a result two main purposes were specified: a communication device for the students and their friends and family back home, and (once the blog had been edited) a record of their experiences for them to use for professional and personal development. A number of prompts were used to guide students to reflect on various aspects of their experience, including communication and teamwork, critical cultural incidents, and progress on their engineering projects.

A third component of the learning outcomes assessment of this experience involved the South African students. At the end of the program they were asked to write a short paper reflecting on 
what they had learned. Prompts were developed in collaboration with the ILLINOIS and UKZN supervising professors and the educational specialist. Table 1 summarizes the assessments.

\begin{tabular}{|l|l|}
\hline \multicolumn{2}{|l|}{ Assessment Methods and Purposes: Illinois - UKZN Engineering Project } \\
\hline Method (*=new in 2008) & Purpose \\
\hline Pre-departure paper* & Individual goal-setting \\
\hline Pre-departure progress report & Synthesis: technical progress on project (written) \\
\hline Blog* & $\begin{array}{l}\text { Critical thinking about experience, documenting experiences in } \\
\text { real time }\end{array}$ \\
\hline Group presentation in SA & Synthesis: technical progress on project (oral) \\
\hline Final technical report & Synthesis: technical progress on project (written) \\
\hline Survey & Standard college-level program assessment \\
\hline $\begin{array}{l}\text { Oral presentation in } \\
\text { ILLINOIS }\end{array}$ & Conveying highlights of experience to others in the department \\
\hline Final reflection paper* & (new for UKZN students) Critical thinking about experience \\
\hline Group interview* & Program assessment - feedback for program coordinators \\
\hline
\end{tabular}

Table 1. Assessment methods.

Research questions and design

We investigated Illinois students' perspectives on their learning processes in their project abroad, based on their pre-departure paper, blog, final reflection papers, and group interview. We also examined UKZN students' final reflection papers. Specifically, we asked: What evidence do students provide in their reflections of their development as engineers? What are students' perspectives on this project-abroad program, and how it could be improved in the future? Data were gathered from seven undergraduate engineering students from the Illinois, and ten undergraduate engineering students from UKZN.

Data analysis and results

In order to examine the students' learning experiences, a content analysis was undertaken of the pre-departure papers (Illinois students) and final reflection papers (Illinois and UKZN students). An emergent coding scheme was used; after preliminary examination of the texts, the researchers determined that most of the comments related to student learning could be mapped well onto components of the Redish and Smith framework depicted above in Figure 1.

Results of the content analysis indicate that all but four of the components of the Redish and Smith framework had at least one student comment. Given the context of the experience, it was 
not surprising that the categories of "entrepreneurial and intrapreneurial," "science and math," recognize and manage change," and "multidisciplinarity" were not represented.

The categories of teamwork, communication, and design/problem-solving were the most salient across all student papers. Often individual comments referred to two or more of these dimensions at once. Examples of typical comments include:

"Team working showed to be very important, because it opens more ideas as you brainstorm together, and you get to make more informed decisions which later you regret less or rarely." (UKZN student)

"Through communicating with everyone on my team, and trying to organize times for people to work, I learned much about the difficulties of completing an engineering project as a part of a team, with a deadline." (Illinois student)

"Since everyone was frustrated at times with their project, I was really impressed how students from different groups would sit down with each other and talk about their issues and troubleshoot them together." (Illinois student)

"Many people don't understand that research is a process, and that there are several mistakes and setbacks along the way, no matter how carefully you plan.” (Illinois student)

"It was interesting to see how two groups with essentially the same information could come to two very different solutions to the same problem. At the same time, our different designs did have a lot of similar features." (Illinois student)

Further analysis of the comments related to teamwork and communication pointed toward the construct of social capital as relevant to these students' experiences. Social capital has been defined as "a variety of entities with two elements in common: they all consist of some aspect of social structure, and they facilitate certain actions of actors... within the structure. ${ }^{24}$ In other words, social capital "consists of social networks, social norms, and the value of these networks and norms for achieving mutual goals," as represented in Figure 2 below: ${ }^{25}$

\begin{tabular}{|c|l|l|l|}
\hline & & \multicolumn{2}{|c|}{ Individual Associations } \\
\hline $\begin{array}{c}\text { Trust, reciprocity, } \\
\text { mutual respect }\end{array}$ & High & $\begin{array}{l}\text { High } \\
\text { Students work together with } \\
\text { minimal barriers. }\end{array}$ & $\begin{array}{l}\text { Students may want to work } \\
\text { together but do not have a } \\
\text { reason to, i.e. assignments } \\
\text { are trivial }\end{array}$ \\
\cline { 2 - 4 } & Low & $\begin{array}{l}\text { Students work together but } \\
\text { are leery due to factors such } \\
\text { as competition. }\end{array}$ & No trust or interaction. \\
\hline
\end{tabular}

Figure 2. Dimensions of social capital (From Brown et al., 2004). 
Social capital is important for engineering students' retention and academic achievement; ${ }^{26}$ therefore the salience of this theme in the present data merits further consideration. Both the Illinois and South African students emphasized the value of individual associations and socializing:

"I made many new friends on this trip, both from UKZN and the US...I especially appreciate R. for all the time he put into showing us around... He really went the extra mile to help us have fun." (Illinois student)

"We had fun almost every time that we went to the farm for the construction process." (UKZN student)

"The best advice that I can give to students who are going to participate in projects like this in the future is that they should enjoy the experience and interact as much as possible with their visiting team members. This interaction should not only take place for the design project purposes but should also be on a social level." (UKZN student)

Comments about trust, reciprocity, and mutual respect were also common:

"I have gained insights into the dynamics of peer groups... I have become more aware of what I might do to bother people around me." (Illinois student)

"It is very important that before carrying on with any project work, that all the team members understand the whole project and that their presence must be valued and honored." (UKZN student)

"I felt comfortable and valued as a team member... We were able to rely on each other and trust that each person would fully apply themselves in their tasks." (UKZN student)

Students also described how these dimensions of social capital directly affected the way the engineering work was accomplished:

"In our microalgae group, during construction we were doing one task at a time and this was really consuming time and wasting resources. On the other hand it made the other members feel left out of the whole project. I am glad to say that this was noticed earlier and the matter was resolved." (Illinois student)

"It is fairly difficult to work on a team, as there are many disagreements about what should be done. It has been a growing experience for myself... as I have learnt how to deal with people and how to overcome obstacles." (UKZN student)

Two additional categories from Redish and Smith were prevalent in the South African students' reflection papers: "strong work ethic" and "integration of analytical, problem solving, and design skills:" 
"The values and morals of the American students, regarding work ethic and perseverance, proved to be similar to the RSA students, which was most rewarding."

"It is also nice to be able to use all the different techniques and skills learnt over the period of our degree, and to implement them in a practical way. Our design project covers many aspects that we have learnt about and techniques have been used from what we have studied."

Following are example comments from Illinois and UKZN students in some of the other (less common) categories:

Working in diverse environments:

"While I have worked in several groups before, the vast majority of the people that the groups were comprised of were either good friends, acquaintances, or at least similar in ideologies. This time I find myself working with three strangers who are very much unlike me, and while this is probably the biggest challenge I will face, it is because of that that it is probably the best thing for me." (Illinois student)

Synthesize engineering, business, and societal perspectives:

"Not only do we have to create a device that will be extremely useful to a lot of people, but we have to make it on a very limited budget. Money constraints force you to think a little bit harder about how you are going to do things, and are also grounds for trade-offs; an engineer has to decide which of two traits is most logical to have in a design." (Illinois student)

Ethically responsible in a global... context:

"The UKZN projects have a much higher potential to directly impact people's lives. The resulting products of those projects can be taken directly to people in rural areas in South Africa for use in their daily lives." (Illinois student)

Adaptability:

"Probably the most important thing I have learnt is that not everything goes according to plan whether it be due to inefficiencies within the team, or problems which are impossible to prevent, for example the ordering of materials." (UKZN student)

Beyond the Redish and Smith framework, the Illinois students also wrote a great deal about what they learned about South Africa, its culture, and broader experiences that cause them to reflect on their normal lives:

"Eating the cheap foods which university students can survive on (roti rolls, bunny chow, pies) was quite enjoyable."

"I didn't comprehend the scope of the AIDS epidemic in Africa until I had a conversation with one of our hosts. Her housekeeper was preparing to visit her family in Zimbabwe, where many of her family members had AIDS or had already died of the disease." 
"I now [upon return] have to address the personal question, 'How do I relate my experience to those around me?"”

However, a great deal more of this sort of comment appeared in the students' blog. In addition to the students' pre-departure and post-experience papers, a weblog ("blog") was also experimented with in this program. Limited access to the internet prevented students from using the blog as much as they wanted, but it still proved to be a valuable forum for student reflection. Students used the blog for the following purposes:

- Introducing their South African teammates.

- Commenting on their perceptions of South African culture.

- Sharing things they learned about the local languages and politics (one student inserted a video clip of one of her South African teammates demonstrating Zulu clicks).

- Documenting the design process and problems with their projects.

- Discussing the ups and downs of their day-to-day experiences.

It also appeared that the use of the blog contributed to social capital development among the students. The Illinois students' descriptions of their South African teammates revealed positive social interactions, and the overall tone of many of the posts conveyed humor, camaraderie, and general excitement about their experiences.

A group interview was selected as an informal way of obtaining feedback about the effectiveness of the program. It allowed the students to offer their impressions in a group setting in which it was hoped that individual responses would also stimulate or prompt inputs that may not have been provided if the students had been interviewed on their own. The interview took place a few months after the students had returned from South Africa so that they had time to reflect on the visit and its impact on them.

Four questions were posed to the group, the first being what aspects of the trip were positive or beneficial and therefore should be retained in future trips. While some students expressed satisfaction with "everything", the excursions were singled out as a major highlight. They also liked living together in the bed and breakfast accommodation, which allowed them to "bond" with each other, even though it somewhat prevented them from branching out and experiencing the different South African culture.

The second question was about the most challenging aspects of the trip. The only factor raised concerned the timing of the visit relative to the availability of the South African students, who were busy with classes for two of the three weeks during which they had significant interactions. Some blocks of time were set aside for project work during the week after classes had begun, but it would have been preferable to have full days allocated to the projects.

In the third question the students were asked what should be changed in the program to make it better. A number of suggestions were provided. With regard to preparation for the trip, it was recommended that an informal team-building activity be instituted right at the beginning of the program to help students get to know each other as well as begin working on the projects as early as possible. Also students should be encouraged to exchange preliminary project details for example with the aid of photographs. In addition, some knowledge about laboratory and 
workshop facilities in South Africa beforehand would have been useful in terms of preparations related to fabrication and construction work. From a communication standpoint, more than one video conference was regarded as necessary and holding such a conference soon after the formation of the teams was recommended. It was also suggested that more regular communication between team members be prescribed either via email or through group phone or web-based conferences.

There was also a suggestion to build in more social time with the South African students, for example inviting them to socialize at the bed and breakfast facility. With respect to logistical issues, better coordination of transportation to and from the laboratory and workshop facilities was recommended so that students did not waste time waiting for rides. Also, instructions as to what to pack and bring on the trip should be more specific so that students do not bring an excessive amount of luggage and clothes.

Finally some comments were sought on how effective the blog was. Students indicated that it was frustrating writing on the blog because the internet access was too slow. An off-line electronic journal would be a possible alternative in this case.

\section{Discussion and conclusions}

Based on evidence from the reflection papers and the blog, all students in this program demonstrated development in and/or increased awareness of many skills required of today's engineers. This cross-cultural, project-centered service-learning experience provided an authentic context for students to integrate teamwork, communication skills, problem solving, and cultural awareness. Evidence of development of other engineering skills (e.g. leadership and curiosity) was more varied across individuals. In this regard the Redish and Smith framework proved valuable in analyzing students' comments about their experiences.

The notion of social capital is also salient in these students' reflections, and should be recognized as a relevant component to other similar curricular and co-curricular engineering experiences, such as internships, coops, and capstone design projects.

It is also important to realize that learning is taking place through the assessments themselves. Critical reflection is a metacognitive activity that generates, deepens, and documents learning through "a continual interweaving of thinking and doing"27,28 Critical reflection may be a characteristic of "curious and lifelong learners" in Redish and Smith's framework (and in ABET's criterion i). It is also related to Pascarella and Terenzini's interpretation of reflective thinking: "a kind of thinking that engineers draw on in high-level analytic problem solving."29 We suggest that future frameworks that describe attributes of engineers more explicitly include the ability to critically reflect on one's learning and one's work.

The group interview was valuable for (a) allowing students to reflect on their learning in a group context, and (b) informing the program coordinators about the positives and negatives about the experience. Students' ideas about what to keep and what to change have influenced program planning for the next year. Furthermore, the theme of social capital was again salient in their 
comments about bonding, the desire for more interactions with UKZN students before arrival, and the relevance of the social activities and excursions to the entire experience.

According to the AAHE Assessment Forum principles, "Assessment works best when it is ongoing and not episodic." ${ }^{30}$ While the assessment processes and results of this project are helpful for understanding student learning and for program development, our experiences also point to areas for further work. These include:

- Further refinement of student reflection paper prompts that elicit the kinds of observations that are relevant for analyzing how and what engineers learn in this context.

- Further exploration of the roles of social capital and cross-cultural communication in projects abroad.

- Investigations of cooperating faculty members' experiences in developing and mentoring students in this context.

\section{References}

1 Astin, A., Banta, T., Cross, P., El-Khawas, E., Ewell, P., Hutchings, P1, Marchese, T., MeClenney, K., Mentkowski, M., Moran, E., and Wright, B. (1991). Nine principles of good practice for assessing student learning. Washington DC: American Association of Higher Education. Available at http:/www.facet.iupui.edu/resources/AAHE\%20Principles.pdf . Accessed 1 February 2009.

${ }^{2}$ National Academy of Engineering. (2004). The engineer of 2020: Visions of engineering in the new century. Washington DC: National Academies Press, pp. 51, 55.

3 Sheppard, S., Macatangay, K., Colby, A., and Sullivan, W. (2009). Educating engineers: Designing for the future of the field. San Francisco, CA: Wiley/Jossey-Bass.

${ }^{4}$ National Academy of Engineering. (2005). Educating the engineer of 2020: Adapting engineering education to the new century. Washington DC: National Academies Press.

5 Redish, E., and Smith, K. (2008). Looking beyond content: Skill development for engineers. Journal of Engineering Education 97(3), pp. 295-308.

${ }^{6}$ Parkinson, A. (2007). Engineering study abroad programs: Formats, challenges, and best practices. Proceedings of the 2007 American Society for Engineering Education Annual Conference and Exposition. American Society for Engineering Education.

${ }^{7}$ Mello, N., DiBiasio, D., and Vaz, R. (2007). Fulfilling ABET outcomes by sending students away. Proceedings of the 2007 American Society for Engineering Education Annual Conference and Exposition. American Society for Engineering Education.

${ }^{8}$ DiBiasio, D., and Mello, N. (2004). Multilevel assessment of program outcomes: Assessing a nontraditional study abroad program in the engineering disciplines. Frontiers: The Interdisciplinary Journal of Study Abroad, 10, pp. 237-252.

${ }^{9}$ Lohmann, J., Howard, A., and Hoey, J. (2006). Defining, developing and assessing global competence in engineers. European Journal of Engineering Education, 31(1), 119-131.

10 Mayhew, M., Eljamal, M., Dey, E., and Pang, W. (2005). Outcomes assessment in international engineering education: Creating a system to measure intercultural development. Proceedings of the 2005 American Society for Engineering Education Annual Conference and Exposition. American Society for Engineering Education.

11 Slivovsky, L., DeRego, F., Jamieson, L., and Oakes, W. (2003). Developing the reflection component in the EPICS model of engineering service learning. Proceedings of the 2003 ASEE/IEEE Frontiers in Engineering Education Conference. 
12 Devon, R.F., Lesenne, J., Hager, W. and Saintive, D. (1998). Student outcomes of international collaborations. Proceedings of the 1998 International Conference on International Engineering Education.

13 Astin et al. (1991). Ibid.

${ }^{14}$ Dym, C., Agogino, A., Eris, O., Frey, D., and Leifer, L. (2005). Engineering design: Thinking, teaching, and learning. Journal of Engineering Education, 94(1), pp. 103-120.

${ }_{15}$ Smith, K., Sheppard, S., Johnson, D., and Johnson, R. (2005). Pedagogies of engagement: Classroom-based practices. Journal of Engineering Education, 94(1), pp. 87-101.

${ }^{16}$ Sheppard et al. (2009). Ibid., p. 117.

${ }^{17}$ Sheppard et al. (2009). Ibid.

${ }^{18}$ Tsang, E. (2000). Introduction. In Tsang, E. (Ed.), Projects that matter: Concepts and models for service-learning in engineering. Washington DC: American Association of Higher Education, pp. 1-12.

${ }^{19}$ Moffatt, J., and Decker, R. (2000). Service-learning reflection for engineering: A faculty guide. In Tsang, E. (Ed.), Projects that matter: Concepts and models for service-learning in engineering. Washington DC: American Association of Higher Education, pp. 31-40.

${ }^{20}$ Hansen, A., Bohn, A., and Smithers, J. (2005). Study abroad experience in South Africa through short-term collaborative projects. Proceedings of Frontiers in Education Conference, American Society for Engineering Education, Indianapolis, Indiana, Session S1D, p10-14.

${ }^{21}$ Hahn, L., Hansen, A., and Kalita, P. (2008). Learning outcomes assessment for project-based study abroad programs in developing countries. ASABE Paper No. 080021, Proc. American Society of Agricultural and Biological Engineers Annual International Meeting, Providence, Rhode Island.

22 Astin et al. (1991). Ibid.

${ }^{23}$ National Academy of Engineering. (2004). Ibid.

${ }^{24}$ Coleman, J. (1988). Social capital in the creation of human capital. American Journal of Sociology, 94, pp. 95120.

${ }^{25}$ Brown, S., Flick, L., and Williamson, K. (2004). Social capital in engineering education. Proceedings of the 2004 ASEE/IEEE Frontiers in Engineering Education Conference.

${ }^{26}$ Brown et al. (2004). Ibid.

27 Schön, D. (1983). The reflective practitioner: How professionals think in action. London: Temple Smith.

${ }^{28}$ Clayton, P., and Whitney, B. (2008). Research on and through reflection in international service learning. Paper presented at the Third Annual International Service-Learning Conference, IUPUI, March 2008.

${ }^{29}$ Pascarella, E., and Terenzini, P. (2005). How college affects students: A third decade of research. San Francisco: Jossey-Bass. P. 37.

30 Astin et al. (1991). Ibid. 